\title{
Regional anesthesia for the trauma patient: improving patient outcomes
}

\author{
This article was published in the following Dove Press journal: \\ Local and Regional Anesthesia \\ 12 August 2015 \\ Number of times this article has been viewed
}

\author{
Jeff Gadsden \\ Alicia Warlick \\ Department of Anesthesiology, Duke \\ University, Durham, NC, USA
}

\begin{abstract}
Trauma is a significant health problem and a leading cause of death in all age groups. Pain related to trauma is frequently severe, but is often undertreated in the trauma population. Opioids are widely used to treat pain in injured patients but have a broad range of undesirable effects in a multitrauma patient such as neurologic and respiratory impairment and delirium. In contrast, regional analgesia confers excellent site-specific pain relief that is free from major side effects, reduces opioid requirement in trauma patients, and is safe and easy to perform. Specific populations that have shown benefits (including morbidity and mortality advantages) with regional analgesic techniques include those with fractured ribs, femur and hip fractures, and patients undergoing digital replantation. Acute compartment syndrome is a potentially devastating sequela of soft-tissue injury that complicates high-energy injuries such as proximal tibia fractures. The use of regional anesthesia in patients at risk for compartment syndrome is controversial; although the data is sparse, there is no evidence that peripheral nerve blocks delay the diagnosis, and these techniques may in fact facilitate the recognition of pathologic breakthrough pain. The benefits of regional analgesia are likely most influential when it is initiated as early as possible, and the performance of nerve blocks both in the emergency room and in the field has been shown to provide quality pain relief with an excellent safety profile.
\end{abstract}

Keywords: trauma, injury, nerve block, regional anesthesia, outcomes

\section{Introduction}

Trauma is a significant public health problem, accounting for $30 \%$ of all life years lost in the US - more than cancer, heart disease, and HIV combined. ${ }^{1}$ It is the leading cause of death for the age group 1-44 years, and the third leading cause of death for all age groups. ${ }^{1}$ The economic burden of trauma exceeds $\$ 400$ billion in the US annually. This review aims to discuss the role of regional anesthesia within the overall framework of pain management in trauma, explore several examples of where regional anesthesia may affect outcomes in specific injuries, and briefly address this issue of acute compartment syndrome (ACS) in the context of neural blockade.

\section{Part I: the role of regional anesthesia in trauma Acute pain in trauma}

The management of pain in the acutely injured patient can be challenging. Resuscitation and the assessment and treatment of life-threatening injuries are first priority in a trauma patient, and provision of adequate analgesia must frequently be delayed until the patient is stable. However, there is increasing evidence that the pain associated with injury is undertreated, a condition termed "oligoanalgesia". ${ }^{2}$ There are multiple barriers to
Department of Anesthesiology, Duke University Medical Center, 230I Erwin

Road, Durham, NC 277I0, USA

$\mathrm{Tel}+19196816437$

Fax + I 9196818994

Email jeff.gadsden@duke.edu 
effective analgesia for trauma patients. Clinicians are often reluctant to administer pain therapies (especially systemic opioids) to trauma patients for fear of provoking hemodynamic instability or respiratory depression and airway compromise. Patients with neurologic injury require frequent reassessments, which may be impaired or obscured with systemic opioids. Opioid-induced delirium is also a concern, particularly in the elderly population. Trauma patients are frequently unable to communicate due to the need for sedation, mechanical ventilation, etc, which can impair adequate pain assessment.

In a study of 36 Australian emergency departments, patients who presented with hip fracture $(n=645)$ were found to have a mean time to first treatment of their fracture-related pain of 126 minutes. ${ }^{2}$ Reported barriers included confusion/ dementia, comorbidities such as head injury or hypotension, patient refusal, and language or communication problems. Notably, only $7 \%$ of these patients received a femoral nerve block. Another study of patients presenting to the emergency department with predominantly injuries of the extremities showed that while $91 \%$ had pain on admission (mean numeric rating scale 5.9), 86\% still had pain upon discharge (mean numeric rating scale 5.0); pain actually increased in $17 \%$ at the time of discharge. ${ }^{3}$ Of the total 450 patients in this study, only $19 \%$ received any type of pharmacologic pain therapy. These data speak to the widespread undertreatment of pain in trauma patients, even those whose injuries are not life-threatening.

The most common approach to pain management in trauma patients is intravenous (IV) opioids. While opioids are excellent analgesics, work quickly, and are a rational choice when patients have multiple injuries, they carry a significant burden of potential adverse effects, which include: ${ }^{4}$

- respiratory depression

- vasodilation and hypotension (especially in hypovolemia)

- delirium

- nausea and vomiting

- constipation

- pruritus

- immunosuppression

- increased staffing requirement to monitor patient (due primarily to respiratory depression)

- increased length of stay in emergency department or recovery room

Multimodal analgesia is increasingly becoming a standard for treating pain in a wide variety of elective surgical patients, where it leads to a reduction in opioid requirements and opioid-related adverse effects. ${ }^{5,6}$ One difference between the trauma and elective surgical populations is the frequent inability to utilize the oral route for medications due to sedation, neurologic impairment, or the presence of an airway device. For this reason, common multimodal agents used in the care of trauma patients include IV ketamine, acetaminophen, ketorolac, clonidine, and dexmedetomidine.

\section{Where does regional anesthesia fit in?}

Approximately, $60 \%$ of multiply injured patients with an Injury Severity Score greater than 16 have an extremity injury, and $30 \%$ have two or more extremity injuries. ${ }^{7}$ Twenty percent of multiply injured patients have both upper and lower extremity injuries. Since the majority of regional anesthesia procedures involve the extremities, their role in analgesia for trauma patients seems well suited.

The principal benefit of regional anesthetic techniques, and peripheral nerve blocks in particular, is the provision of high-quality analgesia that is site-specific and devoid of any systemic side effects. Regional anesthesia confers several other advantages over systemic analgesic therapies for trauma patients (Table 1).,8-19

The development of chronic pain is a significant problem following acute injury. Up to $77 \%$ of patients who incur severe musculoskeletal trauma will report post-traumatic chronic pain, defined as pain lasting greater than 3 months from the time of injury. ${ }^{20}$ There are multiple risk factors that contribute to the likelihood of transitioning from acute to chronic pain. These include age, comorbid medical conditions, depression or anxiety states, and alcohol and tobacco consumption. However, the risk factor that appears to be most predictive of eventual chronic pain is the intensity of acute pain at the time of injury (odds ratio between 2.4 and 11.2). ${ }^{21,22}$ Regional anesthesia has been shown to significantly reduce acute pain intensity in traumatic

Table I Potential advantages of regional analgesia over systemic therapies

Decreased adverse effects compared to some conscious sedation techniques (eg, hypoxia, agitation, nausea/vomiting) $)^{8,9}$

Decreased need for sedatives, an improved neurologic assessment ${ }^{10}$ Reduction in opioid requirement and ORAEs ${ }^{11,12}$

Reduction in length of stay in emergency or critical care units ${ }^{13,14}$ Improved comfort and safety for transport ${ }^{10,15}$

Decreased need for staffing (secondary to decreased need for monitoring compared to procedural sedation) $)^{14,16}$

Reduction in the stress response to injury ${ }^{17,18}$

Decreased cost compared with conscious sedation (largely related to monitoring and staffing costs) $)^{19}$

Abbreviation: ORAEs, opioid-related adverse events. 
injury. ${ }^{23}$ While it is attractive to assume that quality regional blockade early in the course of an injury would prevent the development of chronic pain, the evidence supporting this is very weak at present and randomized, controlled studies are needed..$^{20}$ Notwithstanding, there is little downside to providing high-quality analgesia in the acute setting with regional blocks. If there is, in fact, some long-term analgesic advantage that has yet to be elucidated, the patient may incur that additional benefit.

\section{Continuous peripheral nerve blockade in trauma}

Continuous peripheral nerve block (CPNB) techniques prolong the duration of analgesia well beyond 16-24 hours that can be expected from a single-injection nerve block with long-acting local anesthetics such as ropivacaine or bupivacaine. The pain intensity associated with trauma is often severe and longstanding, making CPNBs a useful tool. Catheters can be left in for days to weeks, depending on the indication. Patients with complex injuries that require repeated debridement, fracture fixation, and/or skin grafting frequently benefit from such long-term catheterization (Figure 1). The pumps can be programmed to deliver a background infusion of a low concentration, long-acting local anesthetic (eg, $0.1 \%-0.2 \%$ ropivacaine) while on the floor or intensive care unit (ICU), and the catheters manually bolused with a higher

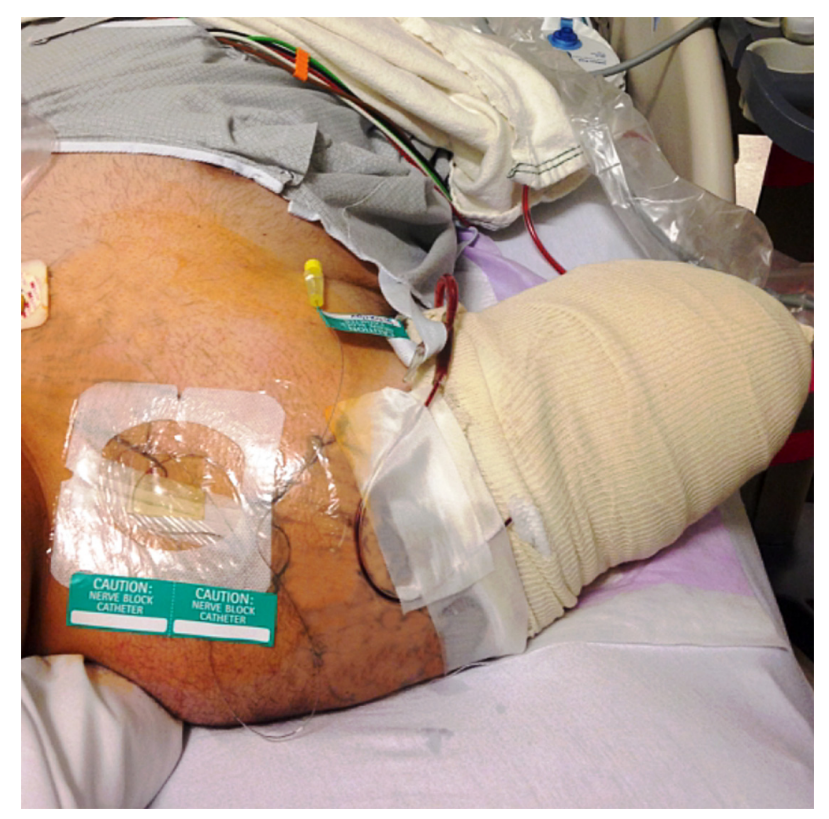

Figure I Patient who had suffered a traumatic amputation of the mid-humerus following a motorcycle crash.

Notes: An infraclavicular catheter was placed prior to his initial surgical procedure and kept for 6 days, facilitating pain relief and multiple return trips to the operating room for debridement. concentration solution upon return to the operating room to provide surgical anesthesia. Buckenmaier et al described a series of 187 patients injured in combat who were treated with CPNBs for a median of 8 days (range, 1-33 days); catheter-specific complications were rare (3.7\%) and included kinking, dislodgement, and superficial infection. ${ }^{24}$ It should be noted that these data reflect a specific patient population: healthy, fit young soldiers. Catheter techniques in the elderly, unhealthy civilian trauma victim may come with additional challenges, although there are limited data to suggest that these techniques are less safe when used in a group of a certain age or physical status.

Infection is a concern when using an indwelling catheter in the trauma population, since these patients are at risk for bacteremia and sepsis, and procedures are often performed in less than ideal environments such as the emergency room and/or ICU. Capdevila et al demonstrated that injured patients admitted to a trauma ICU were five times more likely to develop a CPNB catheter infection than elective surgical patients. ${ }^{25}$ Other factors reported to increase the risk of catheter infections include duration of catheter use for more than 48 hours, the use of prophylactic antibiotics, insertion at the femoral or axillary location, and frequent dressing changes. ${ }^{25-29}$ Catheter type may also play a role in the development of infection. Lai et al reported a case series of two superficial and four deep infections, where the deep infections requiring operative incision and drainage were associated with stimulating catheter use. ${ }^{30}$ The authors hypothesized that repetitive movements of a catheter with an internal metal coil could result in microhematoma formation, providing a rich culture medium for hematogenously spread bacteria. Despite these data, the overall incidence is still low, with only $0 \%-3 \%$ of all catheters showing evidence of infection.

Since $20 \%$ of multitrauma patients have both upper and lower extremity injuries, the opportunity to use multiple catheters arises frequently. For example, Plunkett and Buckenmaier placed bilateral sciatic nerve catheters and a single femoral nerve catheter in a patient with bilateral leg injuries who was receiving treatment doses of enoxaparin that precluded epidural analgesia. ${ }^{31}$ Care must be taken to consider the dose of local anesthetic that is being delivered in order to prevent toxic plasma levels; however, this is rarely an issue since the concentrations that are used clinically for catheters are low (eg, $0.1 \%-0.2 \%$ ropivacaine). One prospective study of 13 combat trauma patients receiving $0.2 \%$ ropivacaine infusions at $6-14 \mathrm{~mL} / \mathrm{h}$ for a period of 4-25 days showed a median unbound plasma ropivacaine level of $0.11 \mathrm{mg} / \mathrm{L}$ (range, undetectable to $0.63 \mathrm{mg} / \mathrm{L}$ ) over the duration of the 
study with no reports of toxic events. ${ }^{32}$ The toxic unbound plasma concentration of ropivacaine was approximately $0.6 \mathrm{mg} / \mathrm{L} .{ }^{33}$ Two patients had spikes in their plasma levels to this threshold, but both were associated with a $60 \mathrm{~mL}$ bolus of $0.5 \%$ ropivacaine prior to that measurement. Taken together, these data suggest that long-term infusions of ropivacaine at low concentrations are safe in the trauma population. Notwithstanding, multiply injured patients frequently have two catheters infusing simultaneously, which may increase the risk of toxic plasma levels of local anesthetic. Common strategies to mitigate this risk include lowering the concentration of the local anesthetic infusate (ie, ropivacaine $0.1 \%$ or $0.15 \%$ rather than $0.2 \%$ ), and/or relying more on periodic intermittent boluses rather than a high-rate continuous background infusion.

\section{Regional analgesia for trauma outside the operating room}

Nerve blocks have been used effectively in the emergency department for injured patients requiring analgesia for minor procedures. Compared to procedural sedation, upper extremity blocks appear to confer several advantages. Interscalene block for shoulder reduction has been shown to reduce length of stay in the emergency department and the requirement for one-to-one monitoring. ${ }^{14}$ Patients with upper extremity fractures, dislocations, and/or abscesses who received supraclavicular block for their procedure experienced a shorter length of stay without any impact on patient safety or satisfaction. ${ }^{13}$ Ultrasound-guided intercostal blocks have been used safely and effectively for chest drain placement following traumatic pneumothorax. ${ }^{34}$

In most hospitals, anesthesiologists are the physicians most qualified to perform nerve blocks. However, due to work demands and time constraints, anesthesiologists may not be able to attend to patients in the emergency department or critical care unit in a prompt manner, leading to significant delays in providing quality analgesia. Randall et al reported the results of a successful initiative to train orthopedic nurses in the performance of fascia iliaca blockade. ${ }^{35}$ This creation of a "physician extender" improved patient access to effective pain control with the use of a simple and safe procedure that is easily taught.

In some situations, it may be safe and appropriate to provide regional analgesia in the field or while in transport to hospital. This decision has to be made in the context of the skill and experience of the doctors or medics attending to the patient, as well as the nature and severity of the injuries. In North America, where EMS teams are largely staffed by paramedics, EMTs or firefighters as first responders, there is a limited set of interventions available, and the philosophy is "scoop and run". In some other parts of the world, physicians who are highly trained in resuscitative and trauma medicine (often anesthsiologists) perform retrievals by ambulance and helicopter; these tend to be systems that benefit most from on-scene triaging, evaluation, and intervention.

Fascia iliaca block has been reported in multiple studies to significantly reduce pain associated with femoral shaft or neck fractures when performed at the scene of the accident or injury. ${ }^{36-39}$ Advantages to the fascia iliaca block include minimal equipment required (syringe and needle), a simple approach that does not rely on ultrasound or nerve stimulation, and a good safety profile with little chance of puncturing a vessel or nerve. Femoral block has also been reported to be effective in prehospital care, but depends more on the experience and skill level of the operator.

Other block techniques that have been reported to successfully reduce pain intensity prior to arriving at hospital include sciatic nerve block, ${ }^{40}$ interscalene nerve block, ${ }^{41}$ multiple nerve blocks about the elbow, ${ }^{42}$ and digital nerve block. ${ }^{43}$

\section{Part II: outcomes in specific injuries}

\section{Fractured ribs}

Twenty-five percent of annual traumatic deaths result from chest trauma. Rib fractures are the most common injury associated with chest trauma, with an incidence of $12 \%$ of all trauma admissions. ${ }^{44}$ The number of rib fractures are directly related to the associated mortality: $5 \%$ for $1-2$ ribs, $15 \%$ for $3-5$ ribs, and $34 \%$ for $\geq 6$ ribs fractured. ${ }^{44}$ The cause of mortality is related primarily to pulmonary injury such as lung contusion and/or pneumothorax, and delayed pulmonary processes such as pneumonia and acute respiratory distress syndrome. ${ }^{45}$ Fractured ribs are a marker of injury severity, especially in young patients with compliant rib cages where more energy is required to cause a break in the bone.

Rib fractures are very painful and limit the patient's ability to breathe deeply. This shallow tidal breathing and lack of deep inspiratory sighs promote atelectasis, V/Q mismatching, and hypoxemia, leading to pneumonia and respiratory failure. Chest physiotherapy is usually either contraindicated or is ineffective due to the pain in the chest wall. Effective analgesia for patients with rib fractures is the primary management goal for these patients, since operative fixation is typically not performed in most cases. There are several options available for pain management, and the management 
plan should be individualized, as there is no one best modality for all patients. The goal of therapy should be to minimize respiratory depression and optimize respiratory excursion, while minimizing possible side effects or complications of the technical procedure such as local anesthetic systemic toxicity or iatrogenic pneumothorax.

Systemic therapies such as IV opioids are a common option but have the drawback of causing sedation and respiratory depression; in this way, opioids may, in fact, promote respiratory complications while reducing pain at the same time. Nonsteroidal anti-inflammatory drugs can be effective for mild rib fracture pain, but may potentiate bleeding in patients who have vascular injury or are taking anticoagulant medications. Acetaminophen is a fairly safe mild analgesic with few side effects, but its effect is limited in multiple rib fractures where pain intensity is high.

Regional analgesic options for relief of rib fracture pain are multiple. Thoracic epidural analgesia (TEA) is a very effective regional anesthetic technique for broken ribs, especially when injuries are bilateral. The Eastern Association for the Surgery of Trauma has stated that epidural analgesia may improve clinically significant outcomes (Grade B recommendation) and it should be considered the preferred analgesic modality (Grade A recommendation). ${ }^{46}$ Several studies have evaluated the effect of TEA on outcomes. Bulger et al randomized 46 patients with three or more rib fractures to receive either TEA with bupivacaine or IV opioid therapy. ${ }^{47}$ Despite a higher severity of pulmonary injury in the epidural group, the incidence of pneumonia was significantly higher in the opioid group (38\% vs $18 \%$ ). When adjusted for the presence of direct pulmonary injury, the relative risk of pneumonia in the opioid group was sixfold higher. In addition, randomization to epidural analgesia decreased the number of days requiring mechanical ventilation by half. This reduction in ventilator-dependent days has been shown in other randomized controlled studies. ${ }^{48,49}$ TEA also reduces the pain associated with coughing or deep breathing compared with IV opioids or intrapleural bupivacaine. ${ }^{50-52}$

In contrast to these studies, $\mathrm{Wu}$ et al found in a retrospective review of 64 patients with rib fractures that while TEA provided superior analgesia to IV patient-controlled morphine, hospital/ICU length of stay and major morbidity was unaffected. ${ }^{53}$ In addition, a meta-analysis of eight studies $(n=232)$ also failed to show a difference in major outcomes such as mortality, hospital/ICU length of stay, and duration of mechanical ventilation with epidural analgesia, although the studies chosen were heterogeneous, with both lumbar and thoracic epidural sites included, and various combinations of local anesthetic and/or epidural opioid in the infusate. ${ }^{54}$

While TEA may be effective at reducing morbidity and other outcomes in the setting of rib fractures, it is not appropriate for all patients. Contraindications include hypovolemia and hypotension, coagulopathy, head or spinal injury, and sepsis, conditions that are all relatively common in the trauma population. TEA is performed infrequently in patients who are heavily sedated or under general anesthesia because it is felt that the absence of patient feedback may put the patient at risk for a needle-related spinal cord injury. For this reason, the actual impact of TEA on the reduction in ventilatordependent days may be limited, since these patients are likely to be intubated and sedated prior to consultation for pain management.

Paravertebral nerve block (PVB) is an alternative regional anesthetic procedure that provides excellent unilateral (or bilateral, if performed on both sides) analgesia. It is technically easy to perform and can be done bedside in the emergency department, operating room, or in the ICU. PVB can be performed in anesthetized patients since there is no concern regarding spinal cord trauma; likewise, coagulopathy or treatment with anticoagulant therapy is not a contraindication since, while there are small vessels in the paravertebral space, even a fairly significant hematoma would not result in cord compression given the extent and compliance of this space. ${ }^{55}$ A catheter technique is typically employed for fractured ribs, with the needle insertion at the midpoint of the rib levels. The block can then be manipulated to the desired level by the administration of the increasing volumes of local anesthetic. In a randomized study of TEA versus thoracic PVB for unilateral multiple fractured ribs, both techniques were equivalent with respect to pain relief, improvement in respiratory function, and incidence of pulmonary complications. ${ }^{56}$ The risks of the technique are generally small, and include contralateral spread via the epidural space ( $1 \%)$, pneumothorax $(0.5 \%)$, hypotension (5\%), and vascular puncture $(4 \%){ }^{57}$

One distinct advantage to PVB catheters over TEA is the ability to provide long-duration analgesia in the ambulatory setting. Murata et al reported a case of a patient with multiple (T3-T8) unilateral rib fractures who was experiencing intense pain and respiratory distress. ${ }^{58} \mathrm{~A}$ paravertebral catheter provided rapid and long-lasting (60 hours) relief and facilitated discharge home from the critical care unit the day after the block. Similarly, Buckley et al reported that an anesthesiology resident who was experiencing debilitating pain from multiple fractured ribs was able to continue clinical work 
opioid-free while receiving an infusion of local anesthetic through a paravertebral catheter for a total of 18 days. ${ }^{59}$

Other regional techniques have been used but have not been shown to be as effective as either TEA or PVB. Intercostal blocks provide good initial relief, but suffer from a limited duration of action and the need to repeat the procedure.$^{60}$ In addition, the risk of pneumothorax with each level attempted is additive and increases the risk of this complication. Intrapleural block with local anesthetic is similarly limited in efficacy and carries a high risk for rapid systemic absorption of local anesthetic. ${ }^{61}$ Transdermal lidocaine patches placed over rib fracture sites have not been shown to significantly improve pain control in patients with traumatic rib fractures. ${ }^{62}$

\section{Hip fractures}

Hip fracture is a very common injury and is associated with significant morbidity and mortality. Patients with fractured hips tend to be older with multiple medical comorbidities, placing them at higher risk for complications, especially chest infection and heart failure. ${ }^{63}$ Over $95 \%$ of hip fractures are fall-related. ${ }^{1}$ Falls are the leading cause of death in adults $>64$ years of age, with hip fracture as the most serious and costly injury resulting from a fall. ${ }^{64}$

Pain intensity from a fractured hip can be moderate to severe, and because of their peripheral location, are well suited to regional techniques. In a systematic review of
83 studies addressing various analgesic options for hip fractures (including systemic analgesia, traction, multimodal pain management, and neurostimulation), only peripheral nerve blocks were found to be effective at reducing acute pain. ${ }^{65}$

The femoral nerve innervates much of the femur and hip joint (Figure 2). Several studies have demonstrated that a femoral nerve block reduces pain intensity following hip fracture and are valuable adjuncts in this population, allowing patients to sit up, move in bed, deep breathe, and cough with reduced pain while awaiting surgery. ${ }^{66-68} \mathrm{~A}$ Cochrane collaboration review of nerve blocks in patients with hip fractures concluded that femoral nerve block resulted in significant reductions in both pain intensity and opioid requirements both preoperatively and during surgery ${ }^{69}$

Reductions in pain scores and opioid requirements after hip fracture have also been shown with fascia iliaca block, which aims to block the femoral and lateral femoral cutaneous nerve (and possibly the obturator nerve) with one injection; this technique is less technically demanding than femoral nerve block, but when compared to femoral block, fascia iliaca may not provide the same degree of pain relief. ${ }^{68,70}$ This may be due to imprecise placement of the local anesthetic during what is traditionally a landmark technique, relying on spread of a large $(30-40 \mathrm{~mL})$ volume for efficacy. ${ }^{39,71}$ Ultrasound guidance appears to increase the frequency of sensory loss of all three nerves compared to the landmark technique. ${ }^{71}$ Obturator nerve block also appears to

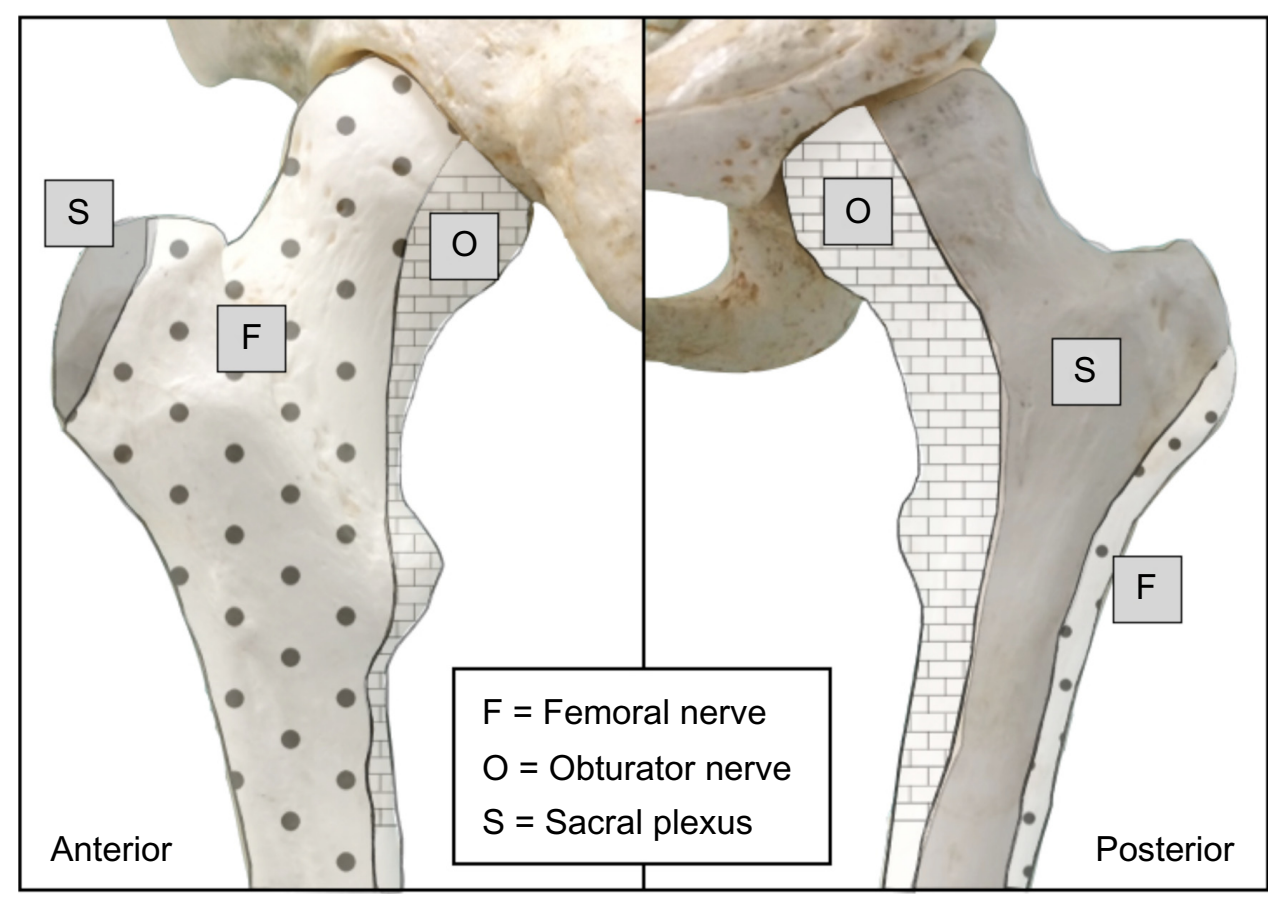

Figure 2 Osteotomal innervation of the head, neck, and proximal shaft of the femur. 
be an effective analgesic technique following hip fracture, which is not surprising given the proportion of the proximal femur and hip joint innervated by this nerve. ${ }^{72}$ However, this technique is not as widely practiced as femoral blockade and even with ultrasound guidance is an intermediate level technique, limiting its widespread use.

Many authors agree on the importance of initiating regional analgesia as early as possible to reduce the opioid burden in hip fracture patients. An increasing number of centers have a hip fracture clinical pathway that includes femoral nerve block placement in the emergency department. Catheter techniques are particularly valuable, since patients with hip fracture may not receive their operative fixation for 48 hours or longer for various medical or logistical reasons. Pedersen et al introduced a care pathway for hip fracture that replaced parenteral opioids with a continuous femoral nerve block in a retrospective cohort study; the nerve block group had a significantly reduced incidence of in-hospital complication (odds ratio $0.61,95 \%$ confidence interval [CI] 0.4-0.9, $P=0.002$ ), as well as significantly reduced rates of confusion and pneumonia. ${ }^{73}$ Mortality was also decreased from $23 \%$ to $12 \%$ in community dwelling patients $(P=0.02)$, but was not affected in patients that presented from nursing homes.

Delirium is common in the elderly, hospitalized patients and is an independent risk factor for death, institutionalization, and dementia after hip fracture. ${ }^{74}$ Two factors that are known to substantially increase the likelihood of delirium are moderate to severe pain and opioids, both of which can be minimized with regional techniques. The impact of regional analgesia on the risk for developing perioperative delirium is unclear, and the absence of effect in some studies likely relates to the complex pathophysiology of delirium. However, there may be specific subpopulations of hip fracture patients that benefit from nerve blocks. Mouzopoulos et al risk stratified hip fracture patients for delirium on admission using a validated instrument, and investigated the effect of daily fascia iliaca block on delirium in intermediate- and high-risk patients. ${ }^{75}$ No difference was seen between high-risk patients who received the block with bupivacaine versus a sham block; in contrast, intermediaterisk patients were significantly less likely to become delirious in the fascia iliaca block with bupivacaine $(2 \%)$ versus sham block (17\%).

Outcomes such as these support the idea that regional analgesic techniques should be initiated as soon as possible in hip fracture patients and continued until pain intensity is sufficiently low that oral nonopioid analgesics are all that are required for pain management.

\section{Digital replantation}

Success following replantation of amputated digits depends on the grafted digit receiving an optimal blood supply while preventing vasospasm and thrombosis. Continuous nerve blocks of the limbs facilitate these goals first and foremost by providing sympathetic blockade, which interrupts injuryinduced vasospasm and allows maximal vasodilation. The profound reduction in afferent input reduces the stress response, which reduces both the tendency toward hypercoagulability and potential thrombotic events, as well as reduces the circulating catecholamines, thereby promoting maximal vasodilation. Acral systolic blood pressure and flow are improved, and the muscle relaxation associated with a continuous nerve block helps to prevent inadvertent movementrelated mishaps with the delicate anastomoses. ${ }^{76}$

Several studies have shown improvements in outcomes with continuous brachial plexus blockade. In one study that randomized patients to continuous supraclavicular block versus parenteral opioids for digit transfer and/or replantation, reoperation rates due to vascular insufficiency were $0 \%$ versus $29 \%$, respectively. ${ }^{77}$ Skin temperature, a prognostic marker of tissue perfusion, is consistently elevated in patients with brachial plexus blocks. ${ }^{78-80}$ Pain scores have also been shown to be improved, as well as the incidence of vasospasm..$^{77,80}$ On the other hand, one study failed to show a difference in overall graft survival at 6 months when continuous brachial plexus block was used. ${ }^{81}$ However, the retrospective nature of this study limits the strength of its conclusions, and additional prospective, randomized studies are needed to clarify the extent of the impact of these techniques on outcomes.

\section{Part III: acute compartment syndrome: a special consideration}

ACS is a serious complication following trauma, occurring when the pressure within a closed compartment rises above a capillary perfusion pressure, compromising the circulation and tissue function within that space. This is typically the result of a high-energy injury to soft tissue, but has been reported with crush or reperfusion injury, exercise, arterial puncture, circumferential dressings, burns, and snake bites. Over one-third of all cases of ACS are associated with tibial fracture, particularly the proximal and middle thirds of the diaphysis (due to the bulkier muscle mass compared with the ankle). Fractures of the forearm are also common injuries that may lead to ACS.

Following capillary collapse, flow into the venous system ceases, leading to tissue hypoxia and the release of 
vascular mediators. The resultant leakage of fluid through capillary and muscle membranes increases edema and worsens the intracompartmental pressure, leading to a vicious cycle of increased pressure $\rightarrow$ ischemia $\rightarrow$ leakage $\rightarrow$ increased pressure (Figure 3). Tissue pressure in muscular compartments is usually $0-10 \mathrm{mmHg}$, and capillary filling pressure is equivalent to diastolic arterial pressure. When the gradient between tissue pressure and diastolic blood pressure falls to within $30 \mathrm{mmHg}$, risk for capillary collapse and development of ACS rises significantly.

The role of regional anesthesia and analgesia in the presence of high-risk injuries is controversial. Many clinicians avoid regional techniques for fear that the neural blockade may mask the developing syndrome, since ACS is traditionally diagnosed on the basis of pain out of proportion to the injury (especially on passive stretch) and paresthesia. ${ }^{82}$ However, these clinical signs and symptoms appear to only have a sensitivity and positive predictive value of $11 \%-19 \%$, while the specificity and negative predictive value are $97 \%-98 \%$ for lower leg injuries. ${ }^{83}$ In other words, the classic clinical findings are more likely to be present in an injured patient without ACS than in a patient with the syndrome. While the absence of clinical signs and symptoms appears to be a reassuring sign, it is unlikely that a patient who has a sufficiently serious injury to be at risk for compartment syndrome would be free of pain, therefore calling into question the utility of the high negative predictive value. In addition, these signs are probably even less useful in the sedated or neurologically impaired patient.

Relatively few case reports have been published relating specifically to peripheral nerve blocks and ACS. However, in all but one of these cases, a nerve block actually facilitated the early detection and prompt treatment of the ischemic limb by the development of new onset breakthrough pain, alerting the clinicians to a change in the status. ${ }^{84-88}$ One case report did assert that a femoral block was responsible for a missed anterior compartment syndrome of the leg following intramedullary nailing. However, the anterior compartment is supplied by the deep peroneal nerve, making femoral block a very unlikely contributing factor. ${ }^{89}$ In contrast to the peripheral nerve blockade, epidural analgesia has been implicated in at least three reports of ACS when dense motor block has been present. ${ }^{82}$ This highlights the need to use dilute solutions of local anesthetics when placing peripheral nerve blocks in trauma patients. Catheter techniques are particularly effective and safe as the concentration of the local anesthetic can be adjusted to match the intervention (surgical procedure vs postoperative pain) or the infusion can be stopped entirely if required. Catheters can be placed at any time during the hospital course and left "dry" (or with a small infusion of saline to prevent clotting), and then bolused when appropriate.

The nature of ACS precludes randomized controlled trials, and it is possible that these events are simply underreported or simply avoided in high-risk patients. Rather than focusing

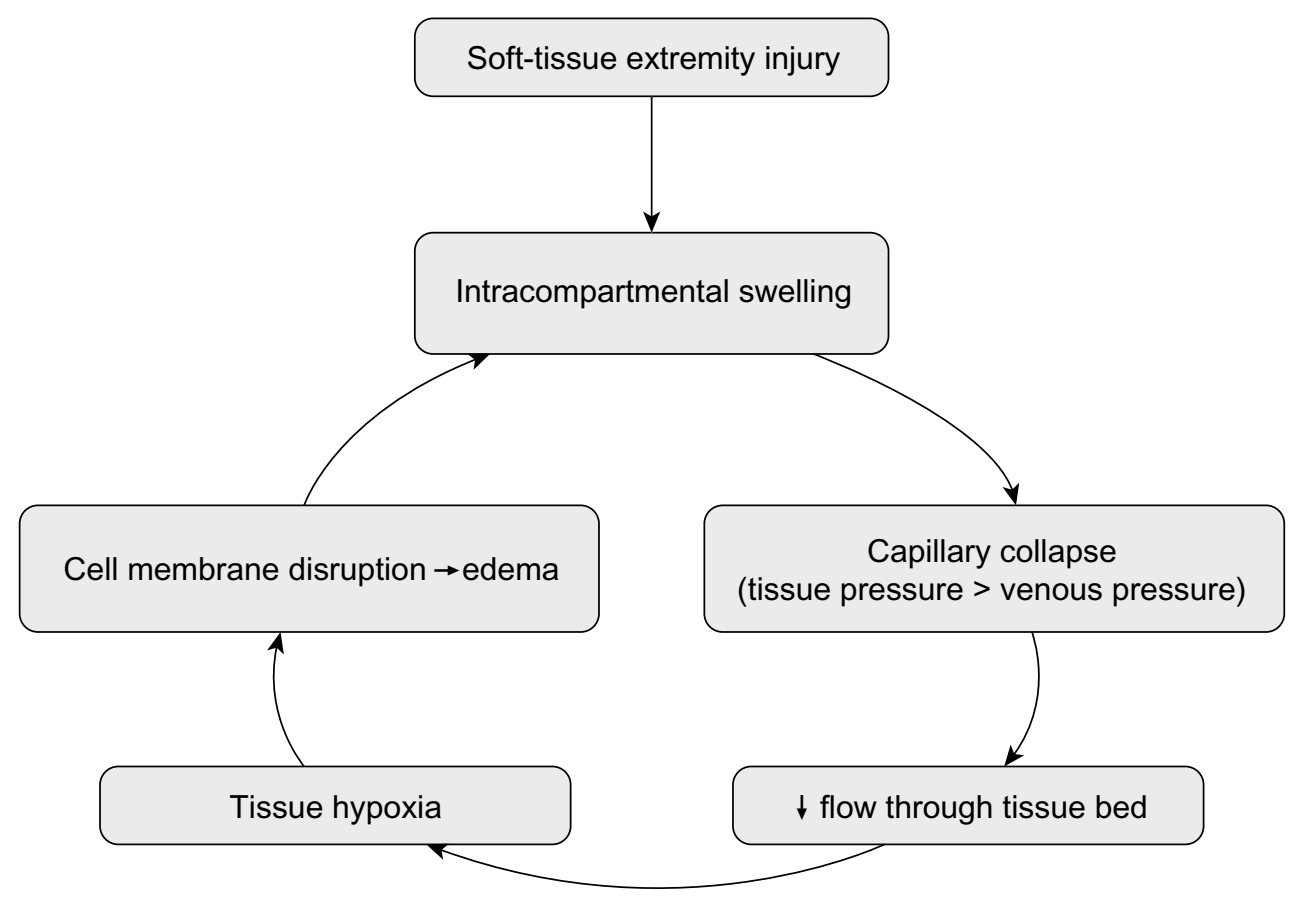

Figure 3 "Vicious cycle" of events leading to increased tissue compartment pressure during acute compartment syndrome. 
on whether to perform a PNB or not, our attention might be better directed toward careful monitoring of analgesic consumption, breakthrough pain, and the use of compartment pressure monitoring for high-risk patients. Vigilance by both surgical and anesthetic teams involved in the patient's care is the key to early detection.

\section{Summary}

Regional anesthesia confers a variety of benefits to trauma patients. In addition to improving patient comfort, peripheral nerve and neuraxial blockade significantly reduces the requirement for systemic opioid analgesia and the adverse effects associated with opioid use. This is often critical in the multiply injured patient who suffers from neurologic, cardiovascular, and/or pulmonary impairment. In addition, the early use of regional anesthetic techniques in selected trauma patients appears to improve outcomes such as pulmonary morbidity, delirium, and mortality, and facilitates reductions in length of stay in both the emergency room and overall hospital admission.

Further research is required to clarify the impact of peripheral nerve blocks and neuraxial analgesia on outcomes such as the development of chronic post-traumatic pain and post-traumatic stress disorder. While peripheral nerve blocks appear not to play a contributory role in diagnostic delay of ACS, the available data is limited, and prudent use of regional techniques in this population should be combined with clinical judgment and careful vigilance.

\section{Disclosure}

The authors report no conflicts of interest in this work.

\section{References}

1. FastStats. Available from: http://www.cdc.gov/nchs/fastats/injury.htm. Accessed March 16, 2015.

2. Holdgate A, Shepherd SA, Huckson S. Patterns of analgesia for fractured neck of femur in Australian emergency departments. Emerg Med Australas. 2010;22(1):3-8.

3. Berben SAA, Meijs THJM, van Dongen RTM, et al. Pain prevalence and pain relief in trauma patients in the Accident and Emergency department. Injury. 2008;39(5):578-585.

4. Choi JJ, Lin E, Gadsden J. Regional anesthesia for trauma outside the operating theatre. Curr Opin Anaesthesiol. 2013;26(4):495-500.

5. Elvir-Lazo OL, White PF. The role of multimodal analgesia in pain management after ambulatory surgery. Curr Opin Anaesthesiol. 2010; 23(6):697-703.

6. Kehlet H, Dahl JB. The value of "multimodal" or "balanced analgesia" in postoperative pain treatment. Anesth Analg. 1993;77(5):1048-1056.

7. Banerjee M, Bouillon B, Shafizadeh S, et al. Epidemiology of extremity injuries in multiple trauma patients. Injury. 2013;44(8):1015-1021.

8. Wathen JE, Gao D, Merritt G, Georgopoulos G, Battan FK. A randomized controlled trial comparing a fascia iliaca compartment nerve block to a traditional systemic analgesic for femur fractures in a pediatric emergency department. Ann Emerg Med. 2007;50(2):162-171, 171. e1.
9. Tezel O, Kaldirim U, Bilgic S, et al. A comparison of suprascapular nerve block and procedural sedation analgesia in shoulder dislocation reduction. Am J Emerg Med. 2014;32(6):549-552.

10. Edwards D, Bowden M, Aldington DJ. Pain management at role 4. J R Army Med Corps. 2009;155(1):58-61.

11. Beaudoin FL, Haran JP, Liebmann O. A comparison of ultrasoundguided three-in-one femoral nerve block versus parenteral opioids alone for analgesia in emergency department patients with hip fractures: a randomized controlled trial. Acad Emerg Med. 2013;20(6):584-591.

12. Neubrand TL, Roswell K, Deakyne S, Kocher K, Wathen J. Fascia iliaca compartment nerve block versus systemic pain control for acute femur fractures in the pediatric emergency department. Pediatr Emerg Care. 2014;30(7):469-473.

13. Stone MB, Wang R, Price DD. Ultrasound-guided supraclavicular brachial plexus nerve block vs procedural sedation for the treatment of upper extremity emergencies. Am J Emerg Med. 2008;26(6):706-710.

14. Blaivas M, Adhikari S, Lander L. A prospective comparison of procedural sedation and ultrasound-guided interscalene nerve block for shoulder reduction in the emergency department. Acad Emerg Med. 2011;18(9):922-927.

15. Hughes S, Birt D. Continuous peripheral nerve blockade on OP HERRICK 9. J R Army Med Corps. 2009;155(1):57-58.

16. Turner AL, Stevenson MD, Cross KP. Impact of ultrasound-guided femoral nerve blocks in the pediatric emergency department. Pediatr Emerg Care. 2014;30(4):227-229.

17. Rung GW, Marshall WK. Nerve blocks in the critical care environment. Crit Care Clin. 1990;6(2):343-367.

18. Lewis KS, Whipple JK, Michael KA, Quebbeman EJ. Effect of analgesic treatment on the physiological consequences of acute pain. Am J Hosp Pharm. 1994;51(12):1539-1554.

19. Miller SL, Cleeman E, Auerbach J, Flatow EL. Comparison of intraarticular lidocaine and intravenous sedation for reduction of shoulder dislocations: a randomized, prospective study. J Bone Joint Surg Am. 2002;84-A(12):2135-2139.

20. Radresa O, Chauny J-M, Lavigne G, Piette E, Paquet J, Daoust R. Current views on acute to chronic pain transition in post-traumatic patients: risk factors and potential for pre-emptive treatments. J Trauma Acute Care Surg. 2014;76(4):1142-1150.

21. Clay FJ, Watson WL, Newstead SV, McClure RJ. A systematic review of early prognostic factors for persisting pain following acute orthopedic trauma. Pain Res Manag. 2012;17(1):35-44.

22. Macrae WA. Chronic post-surgical pain: 10 years on. Br J Anaesth. 2008;101(1):77-86.

23. Buckenmaier CC 3rd, Rupprecht C, McKnight G, et al. Pain following battlefield injury and evacuation: a survey of 110 casualties from the wars in Iraq and Afghanistan. Pain Med. 2009;10(8):1487-1496.

24. Buckenmaier CC 3rd, Shields CH, Auton AA, et al. Continuous peripheral nerve block in combat casualties receiving low-molecular weight heparin. Br J Anaesth. 2006;97(6):874-877.

25. Capdevila X, Bringuier S, Borgeat A. Infectious risk of continuous peripheral nerve blocks. Anesthesiology. 2009;110(1):182-188.

26. Neuburger M, Büttner J, Blumenthal S, Breitbarth J, Borgeat A. Inflammation and infection complications of 2285 perineural catheters: a prospective study. Acta Anaesthesiol Scand. 2007;51(1):108-114.

27. Morin AM, Kerwat KM, Klotz M, et al. Risk factors for bacterial catheter colonization in regional anaesthesia. BMC Anesthesiol. 2005;5(1):1.

28. Cuvillon P, Ripart J, Lalourcey L, et al. The continuous femoral nerve block catheter for postoperative analgesia: bacterial colonization, infectious rate and adverse effects. Anesth Analg. 2001;93(4):1045-1049.

29. Capdevila X, Pirat P, Bringuier S, et al. Continuous peripheral nerve blocks in hospital wards after orthopedic surgery: a multicenter prospective analysis of the quality of postoperative analgesia and complications in 1,416 patients. Anesthesiology. 2005;103(5):1035-1045.

30. Lai TT, Jaeger L, Jones BL, Kaderbek EW, Malchow RJ. Continuous peripheral nerve block catheter infections in combat-related injuries: a case report of five soldiers from Operation Enduring Freedom/Operation Iraqi Freedom. Pain Med. 2011;12(11):1676-1681. 
31. Plunkett AR, Buckenmaier CC 3rd. Safety of multiple, simultaneous continuous peripheral nerve block catheters in a patient receiving therapeutic low-molecular-weight heparin. Pain Med. 2008;9(5):624-627.

32. Bleckner LL, Bina S, Kwon KH, McKnight G, Dragovich A, Buckenmaier CC 3rd. Serum ropivacaine concentrations and systemic local anesthetic toxicity in trauma patients receiving long-term continuous peripheral nerve block catheters. Anesth Analg. 2010; 110(2):630-634.

33. Knudsen K, Beckman Suurküla M, Blomberg S, Sjövall J, Edvardsson N. Central nervous and cardiovascular effects of iv infusions of ropivacaine, bupivacaine and placebo in volunteers. $\mathrm{Br} J$ Anaesth. 1997;78(5):507-514.

34. Stone MB, Carnell J, Fischer JWJ, Herring AA, Nagdev A. Ultrasound-guided intercostal nerve block for traumatic pneumothorax requiring tube thoracostomy. Am J Emerg Med. 2011;29(6):697. e1-e2.

35. Randall A, Grigg L, Obideyi A, Srikantharajah I. Fascia iliaca compartment block: a nurse-led initiative for preoperative pain management in patients with a fractured neck of femur. J Orthop Nurs. 2008;12:69-74.

36. Minville V, Gozlan C, Asehnoune K, Zetlaoui P, Chassery C, Benhamou D. Fascia-iliaca compartment block for femoral bone fracture in prehospital medicine in a 6-yr-old child. Eur J Anaesthesiol. 2006;23(8):715-716.

37. Gozlan C, Minville V, Asehnoune K, Raynal P, Zetlaoui P, Benhamou D. Fascia iliaca block for femoral bone fractures in prehospital medicine. Ann Fr Anesth Reanim. 2005;24(6):617-620.

38. Lopez S, Gros T, Bernard N, Plasse C, Capdevila X. Fascia iliaca compartment block for femoral bone fractures in prehospital care. Reg Anesth Pain Med. 2003;28(3):203-207.

39. McRae PJ, Bendall JC, Madigan V, Middleton PM. Paramedic-performed fascia iliaca compartment block for femoral fractures: a controlled trial. J Emerg Med. Feb 2015

40. Gros T, Amaru P, Basuko C, Dareau S, Eledjam JJ. Sciatic nerve block in prehospital care. Ann Fr Anesth Reanim. 2010;29(2):162-164.

41. Gros T, Delire V, Dareau S, Sebbane M, Eledjam JJ. Interscalene brachial plexus block in prehospital medicine. Ann Fr Anesth Reanim. 2008;27(10):859-860.

42. Lopez S, Gros T, Deblock N, Capdevila X, Eledjam JJ. Multitruncular block at the elbow for a major hand trauma for prehospital care. Ann Fr Anesth Reanim. 2002;21(10):816-819.

43. Simpson PM, McCabe B, Bendall JC, Cone DC, Middleton PM. Paramedic-performed digital nerve block to facilitate field reduction of a dislocated finger. Prehosp Emerg Care. 2012;16(3):415-417.

44. Sharma OP, Oswanski MF, Jolly S, Lauer SK, Dressel R, Stombaugh HA. Perils of rib fractures. Am Surg. 2008;74(4):310-314.

45. Flagel BT, Luchette FA, Reed RL, et al. Half-a-dozen ribs: the breakpoint for mortality. Surgery. 2005;138(4):717-723; discussion 723-725.

46. Simon BJ, Cushman J, Barraco R, et al. Pain management guidelines for blunt thoracic trauma. J Trauma. 2005;59(5):1256-1267.

47. Bulger EM, Edwards T, Klotz P, Jurkovich GJ. Epidural analgesia improves outcome after multiple rib fractures. Surgery. 2004; 136(2):426-430.

48. Ullman DA, Fortune JB, Greenhouse BB, Wimpy RE, Kennedy TM. The treatment of patients with multiple rib fractures using continuous thoracic epidural narcotic infusion. Reg Anesth. 1989;14(1):43-47.

49. Sahin S, Uckunkaya N, Soyal S, et al. The role of epidural continuous pain treatment on duration of intubation, ventilation and ICU stay in flail chest patients. Agri Dergisi. 1993;5:18-20.

50. Pierre E, Martin P, Frohock J, et al. Lumbar epidural morphine versus. Patient-controlled analgesia morphine in patients with multiple rib fractures. Anesthesiology. 2005;103:A289.

51. Luchette FA, Radafshar SM, Kaiser R, Flynn W, Hassett JM. Prospective evaluation of epidural versus intrapleural catheters for analgesia in chest wall trauma. J Trauma. 1994;36(6):865-869; discussion 869-870.

52. Moon MR, Luchette FA, Gibson SW, et al. Prospective, randomized comparison of epidural versus parenteral opioid analgesia in thoracic trauma. Ann Surg. 1999;229(5):684-691; discussion 691-692.
53. Wu CL, Jani ND, Perkins FM, Barquist E. Thoracic epidural analgesia versus intravenous patient-controlled analgesia for the treatment of rib fracture pain after motor vehicle crash. J Trauma. 1999;47(3):564-567.

54. Carrier FM, Turgeon AF, Nicole PC, et al. Effect of epidural analgesia in patients with traumatic rib fractures: a systematic review and meta-analysis of randomized controlled trials. Can J Anaesth. 2009;56(3):230-242.

55. Gadsden J, Kwofie K, Shastri U. Continuous intercostal versus paravertebral blockade for multiple fractured ribs. J Trauma Acute Care Surg. 2012;73(1):293-294.

56. Mohta M, Verma P, Saxena AK, Sethi AK, Tyagi A, Girotra G. Prospective, randomized comparison of continuous thoracic epidural and thoracic paravertebral infusion in patients with unilateral multiple fractured ribs - a pilot study. J Trauma. 2009;66(4):1096-1101.

57. Karmakar MK. Thoracic paravertebral block. Anesthesiology. 2001; 95(3):771-780.

58. Murata H, Salviz EA, Chen S, Vandepitte C, Hadzic A. Case report: ultrasound-guided continuous thoracic paravertebral block for outpatient acute pain management of multilevel unilateral rib fractures. Anesth Analg. 2013;116(1):255-257.

59. Buckley M, Edwards H, Buckenmaier CC 3rd, Plunkett AR. Continuous thoracic paravertebral nerve block in a working anesthesia residentwhen opioids are not an option. Mil Med. 2011;176(5):578-580.

60. Hwang EG, Lee Y. Effectiveness of intercostal nerve block for management of pain in rib fracture patients. J Exerc Rehabil. 2014;10(4): 241-244.

61. Ho AM-H, Karmakar MK, Critchley LAH. Acute pain management of patients with multiple fractured ribs: a focus on regional techniques. Curr Opin Crit Care. 2011;17(4):323-327.

62. Ingalls NK, Horton ZA, Bettendorf M, Frye I, Rodriguez C. Randomized, double-blind, placebo-controlled trial using lidocaine patch $5 \%$ in traumatic rib fractures. J Am Coll Surg. 2010;210(2):205-209.

63. Roche JJW, Wenn RT, Sahota O, Moran CG. Effect of comorbidities and postoperative complications on mortality after hip fracture in elderly people: prospective observational cohort study. $\mathrm{Br} \mathrm{Med} J$. 2005;331(7529):1374.

64. Roudsari BS, Ebel BE, Corso PS, Molinari N-AM, Koepsell TD. The acute medical care costs of fall-related injuries among the US older adults. Injury. 2005;36(11):1316-1322.

65. Abou-Setta AM, Beaupre LA, Rashiq S, et al. Comparative effectiveness of pain management interventions for hip fracture: a systematic review. Ann Intern Med. 2011;155(4):234-245.

66. Beaudoin FL, Nagdev A, Merchant RC, Becker BM. Ultrasound-guided femoral nerve blocks in elderly patients with hip fractures. Am J Emerg Med. 2010;28(1):76-81.

67. Watson MJ, Walker E, Rowell S, et al. Femoral nerve block for pain relief in hip fracture: a dose finding study. Anaesthesia. 2014;69(7):683-686.

68. Temelkovska-Stevanovska M, Durnev V, Jovanovski-Srceva M, Mojsova-Mijovska M, Trpeski S. Continuous femoral nerve block versus fascia iliaca compartment block as postoperative analgesia in patients with hip fracture. Prilozi. 2014;35(2):85-94.

69. Parker MJ, Handoll HHG, Griffiths R. Anaesthesia for hip fracture surgery in adults. Cochrane Database Syst Rev. 2004;(4):CD000521.

70. Newman B, McCarthy L, Thomas PW, May P, Layzell M, Horn K. A comparison of pre-operative nerve stimulator-guided femoral nerve block and fascia iliaca compartment block in patients with a femoral neck fracture. Anaesthesia. 2013;68(9):899-903.

71. Dolan J, Williams A, Murney E, Smith M, Kenny GNC. Ultrasound guided fascia iliaca block: a comparison with the loss of resistance technique. Reg Anesth Pain Med. 2008;33(6):526-531.

72. Rashiq S, Vandermeer B, Abou-Setta AM, Beaupre LA, Jones CA, Dryden DM. Efficacy of supplemental peripheral nerve blockade for hip fracture surgery: multiple treatment comparison. Can J Anaesth. 2013;60(3):230-243.

73. Pedersen SJ, Borgbjerg FM, Schousboe B, et al. A comprehensive hip fracture program reduces complication rates and mortality. J Am Geriatr Soc. 2008;56(10):1831-1838. 
74. Marcantonio ER, Flacker JM, Michaels M, Resnick NM. Delirium is independently associated with poor functional recovery after hip fracture. JAm Geriatr Soc. 2000;48(6):618-624.

75. Mouzopoulos G, Vasiliadis G, Lasanianos N, Nikolaras G, Morakis E, Kaminaris M. Fascia iliaca block prophylaxis for hip fracture patients at risk for delirium: a randomized placebo-controlled study. J Orthop Traumatol. 2009;10(3):127-133.

76. Shanahan PT. Replantation anesthesia. Anesth Analg. 1984;63(8): 785-786.

77. Kurt E, Ozturk S, Isik S, Zor F. Continuous brachial plexus blockade for digital replantations and toe-to-hand transfers. Ann Plast Surg. 2005; 54(1):24-27.

78. Berger A, Tizian C, Zenz M. Continuous plexus blockade for improved circulation in microvascular surgery. Ann Plast Surg. 1985; 14(1):16-19.

79. Su H-H, Lui P-W, Yu C-L, et al. The effects of continuous axillary brachial plexus block with ropivacaine infusion on skin temperature and survival of crushed fingers after microsurgical replantation. Chang Gung Med J. 2005;28(8):567-574.

80. Taras JS, Behrman MJ. Continuous peripheral nerve block in replantation and revascularization. J Reconstr Microsurg. 1998;14(1):17-21.

81. Niazi AU, El-Beheiry H, Ramlogan R, Graham B, von Schroeder HP, Tumber PS. Continuous infraclavicular brachial plexus blockade: effect on survival of replanted digits. Hand Surg. 2013;18(3):325-330.

82. Mar GJ, Barrington MJ, McGuirk BR. Acute compartment syndrome of the lower limb and the effect of postoperative analgesia on diagnosis. Br J Anaesth. 2009;102(1):3-11.
83. Ulmer T. The clinical diagnosis of compartment syndrome of the lower leg: are clinical findings predictive of the disorder? J Orthop Trauma. 2002;16(8):572-577.

84. Walker BJ, Noonan KJ, Bosenberg AT. Evolving compartment syndrome not masked by a continuous peripheral nerve block: evidencebased case management. Reg Anesth Pain Med. 2012;37(4):393-397.

85. Cometa MA, Esch AT, Boezaart AP. Did continuous femoral and sciatic nerve block obscure the diagnosis or delay the treatment of acute lower leg compartment syndrome? A case report. Pain Med. 2011; 12(5):823-828.

86. Uzel A-P, Steinmann G. Thigh compartment syndrome after intramedullary femoral nailing: possible femoral nerve block influence on diagnosis timing. Orthop Traumatol Surg Res. 2009;95(4):309-313.

87. Noorpuri BS, Shahane SA, Getty CJ. Acute compartment syndrome following revisional arthroplasty of the forefoot: the dangers of ankleblock. Foot Ankle Int. 2000;21(8):680-682.

88. Kucera TJ, Boezaart AP. Regional anesthesia does not consistently block ischemic pain: two further cases and a review of the literature Pain Med. 2014;15(2):316-319.

89. Hyder N, Kessler S, Jennings AG, De Boer PG. Compartment syndrome in tibial shaft fracture missed because of a local nerve block. $J$ Bone Joint Surg Br. 1996;78(3):499-500.
Local and Regional Anesthesia

\section{Publish your work in this journal}

Local and Regional Anesthesia is an international, peer-reviewed, open access journal publishing on the development, pharmacology, delivery and targeting and clinical use of local and regional anesthetics and analgesics. The journal welcomes submitted papers covering original research, basic science, clinical studies, reviews \& evaluations,

\section{Dovepress}

guidelines, expert opinion and commentary, case reports and extended reports. The manuscript management system is completely online and includes a very quick and fair peer-review system, which is all easy to use. Visit http://www.dovepress.com/testimonials.php to read real quotes from published authors. 